\title{
A teenager's experience of cancer
}

\author{
Ruth Wawszczyk
}

J R Soc Med 2005;98:370-371

Nothing could have prepared me for the physical and psychological trauma of the past four years. It was in June 2001 that I was taken by ambulance to the oncology ward at the regional children's hospital. For about two months I had been undergoing scans and tests, and biopsies of my lymph glands and bone marrow now showed anaplastic large cell lymphoma. It had spread to my lungs and had also triggered a haemophagocytic lymphohistiocytosis. Within days of being diagnosed, I began the first of seven week-long courses of intensive chemotherapy followed by a further seven months of weekly injections of vinblastine.

When the lymphoma was first diagnosed, a staff nurse asked me what I knew about cancer. My response was simply 'You lose your hair'. It was as well that I did not know what lay ahead of me. Losing my hair was actually one of the least difficult side-effects that I had to contend with. At the time of diagnosis, I was too poorly to take in all that the doctors tried to explain to me about my condition and the treatment protocol. Moreover, for a 14year-old, it is not easy to be on a children's ward - no matter how caring and understanding the staff may be. At a time in adolescence when you are acutely aware of your body, it is very upsetting to be totally reliant on your parents and the nurses for even the most basic washing, toileting and feeding - and without much privacy. Whilst I could appreciate how unwell all the children on the ward were - and that most of them were much younger than myself - the need to have 'lights out' at 8 pm somehow added to the humiliation. Teenagers who have to be in hospital for long periods should have special units - as advocated by the Teenage Cancer Trust.

Whilst my badly swollen glands seemed to respond quite quickly to the chemotherapy and the steroids and my temperature (which had been peaking at $41^{\circ} \mathrm{C}$ for six weeks or more) settled down, I equally quickly began to experience the side-effects of the chemotherapy. At one time my mouth and digestive tract were so ulcerated that I had to have my food pureed like a baby's. I suffered from boils which flared up rapidly and needed treating with intravenous antibiotics. I also got terrible pains in various parts of my body and couldn't even turn over in bed without help. The large amounts of hydration used to flush

Lancaster, UK

E-mail: ruth@wawszczyk20.fsnet.co.uk the chemotherapy drugs through my body caused my heart to race audibly. My blood pressure rose during each week of intensive treatment so that I used to worry that I would not be allowed home on the Saturday night. I became painfully constipated. I also experienced a terrible headache after one of the intrathecal injections of methotrexate. One of the hardest things to cope with, however, was the need to be isolated for four of my week-long courses of chemotherapy because I had contracted an MRSA infection in my Hickman line; apart from the stiffness and pain around the site in my shoulder, it meant that I was cut off from all the other teenagers and children - 'unclean'.

In November 2001, CT scans and bone marrow tests showed no signs of active lymphoma, and the battle was being won. By that time, though, my hair had completely fallen out and my body felt as if it had been ravaged by all the drugs that had been pumped into it. There were times - especially in the dead of night — when I wondered if my body could survive the effects of it all. There still followed, too, seven months of weekly injections of vinblastine. Whilst the side-effects were less severe, they still took a toll on my blood counts and caused me to feel exhausted all the time; I wondered whether my oncefavourite foods would ever taste the same again. My life revolved around weekly visits to the children's hospital for injections, check-ups and scans.

What is hardest to put into words is the huge psychological impact of all that I have been through. Cancer is not what one expects as a teenager. For months I felt as if my life was being taken away from me, and all I wanted was to be 'normal' again. At a time when my friends were busy starting on GCSE courses and planning their futures, I had to get used to complete loss of privacy and powerlessness with every part of my body under scrutiny. It was very hard, too, to see other children suffering, and to have known many who did not survive. I also found it extremely difficult to talk to anyone, apart from my family, about what I was experiencing. When I went back to school my friends were glad to see me, but it was as if a curtain came down between us when I began to try to share the reality of the illness with them. It seemed that they had been advised not to 'hassle' me with questions about what I had been through - all very well meaning but not what I wanted inside. I wanted to be able to speak about life as a cancer patient and life on the ward and what it was 
really like to be faced with a life-threatening illness. As my Macmillan nurse put it, it was as if I had had to grow up very rapidly and face life-and-death issues whilst my peers were still coping with the normal teenage issues such as schoolwork, relationships and increasing freedom. My priorities have changed radically as a result of having anaplastic large cell lymphoma; the illness seems to have opened a rift between myself and many of my peers.

When asked what helped me most to get through these past traumatic years, I have no hesitation in saying it was my consultant at the children's hospital. It was not just his obvious skill as a haematologist, but also his very honest, caring, encouraging and reassuring manner. In a recent article in The Guardian, the journalist Jenni Russell said that, when we are very ill and we encounter the health service 'what we want is for our weakness to be responded to with great care, respect and gentleness. We want to be treated as a human being with an illness, not as a medical problem with an irritating person attached'. That is precisely how I felt: to my consultant and his team I was first and foremost 'Ruth', who happened to be suffering from anaplastic large cell lymphoma, and not simply a 'cancer patient'. Hospital felt like a prison and I needed reassurance as the ordeal proceeded. That is what my consultant gave and continues to give.

Note: A longer version of this paper appeared in the Morecambe Bay Medical Journal 2004;4(9) 